\title{
SYNERGISTIC CORROSION INHIBITION ACTIVITY OF THE CHICORIUMINTYBUS EXTRACT AND IODIDE IONS FOR MILD STEEL IN ACIDIC MEDIA
}

\author{
EMAD E. EL-KATORI ${ }^{a *}$, A. S. FOUDA ${ }^{b}$ AND RAHMA R. MOHAMED ${ }^{b}$ \\ ${ }^{a}$ Department of Chemistry, Faculty of Science, New Valley University, El-Kharja-72511, Egypt. \\ ${ }^{b}$ Department of Chemistry, Faculty of Science, Mansoura University, El-Mansoura-35516, Egypt.
}

\begin{abstract}
Herein, An examination into the corrosion inhibition of mild steel (MS) in $1.0 \mathrm{M} \mathrm{HCl}$ by the Chicoriumintybus extract as a green inhibitor had been achieved via chemical, electrochemical and morphological measurements. The effect of KI additives on corrosion inhibition efficiency was carried out using a weight loss method. The results reveal that the Chicoriumintybus extract inhibited the corrosion reaction by adsorption onto the metal/solution interface. Inhibition efficiency, increased with the Chicoriumintybus concentration and synergistically increased with the presence of KI. The addition of iodide ions to the Chicoriumintybus extract raises inhibition efficiency of 74 to $99 \%$. Polarization data suggest that the Chicoriumintybus extract acts as a mixed inhibition-mechanism. This observation was further corroborated by the fit of experimental adsorption data to the Temkin isotherm. The results were confirmed by AFM, SEM images and ATR-IR for the surface morphology.
\end{abstract}

Keywords: Chicoriumintybus extract; Mild steel; Acid corrosion; Synergistic effect, Surface morphology.

\section{INTRODUCTION}

Iron and its alloys have been one of the majority wasted metals in support of vehicle parts and constructions due to its high malleability [1]. On the other hand, they have been largely liable to corrosion, mainly in acid media. really, acid solutions have been also widely utilized in industrial applications as well as steel and iron, acid pickling, ore creation, chemical processing \& cleaning and oil good acidification. Inhibition by inhibitors has been one of the greatest experiments for metal protection against corrosion constantly in acid media for inhibiting unexpected metal dissolution and acid consuming [2,3]. The inhibitors efficiency has been related to the existence of hetero atoms like $\mathrm{S}, \mathrm{O}$ or $\mathrm{N}$ atoms in applicable molecules, heterocyclic compounds and $\pi$ - electrons [4-6], such chemical inhibitors can adsorbs onto the metal surface and prohibit the active surface sites, therefore lowering the corrosion rate. The polar functional groups have been often observed at the same time as the reaction center for the adsorption process establishment $[7,8]$. The identified risky causes of the most of synthetic organic inhibitors in addition to restricted environmental policy has been produced it essential to investigate a cheaper one, non-toxic and green natural products as eco-friendly corrosion inhibitors [9]. These organic compounds have been produced or extracted from aromatic herbs, spices and medicinal plants. A large amount of natural products origin have been biodegradable, harmless and easily existing in adequate amount as well as gathering the structural considerations. A variety of plant parts for example leaves, fruits, seeds and flowers have been extracted and utilized as corrosion inhibitors [10-20]. Gained data presented from these studies have been confirmed that Chicoriumintybus extract controlled remarkable abilities to restrain the corrosion reaction. Chicoriumintybus extract has been followed Asteraceae family, which has been widely acknowledged for medicinal purposes. Chicoriumintybus the main sesquiterpene lactones are lactucin, 8 deoxylactucin, and lactucopicrin. There are found in the roots and the heads of the plant and are considered to be responsible for the bitter taste of chicory. The leaves and roots also contain traces amount of bitter of other sesquiterpene lactones such as guaianolides, lactupin, deoxylactupin, eudesmonolides and guanomanolides. it has been a local plant in Egypt. Chicoriumintybus has been a major value health food, the whole plant contains a number of medicinally important compounds such as inulin, esculin, volatile compounds (monoterpenes and sesquiterpenes), coumarins, flavonoids and vitamins [21]. It is used as an anti-inflammatory, digestive, diuretic and helps in treatment of spleen enlargement. The plant is used as liver tonic and as an alternative medicine in treating hepato-toxicity. It is used for local application in the treatment of acne, inflammation of throat, and in diarrhea and vomiting $[3,4,22,23]$.

The plan of this work is to check Chicoriumintybus extract action as a green corrosion inhibitor on mild steel in $0.1 \mathrm{M} \mathrm{HCl}$ solution using Weight loss method (WL), Open circuit potential (OCP), Potentiodynamic polarization (PP), Electrochemical impedance spectroscopy (EIS) and Electrochemical frequency modulation (EFM) techniques. Also, attenuated total reflection-infrared spectroscopy (ATR-IR), Scanning electron microscopy (SEM) and Atomic force microscopy (AFM) analyses have been utilized in order to confirm the inhibition mode.

\section{EXPERIMENTAL}

\subsection{Mild steel (MS) sample}

Seven same mild steel samples had been cut out from MS sheets. The listed chemical composition of applicable MS had been (wt \%) $\mathrm{Fe}=99.77, \mathrm{C}=0.06495$. The MS surface samples and the MS working electrode had been glossed as a mirror finish via various grades (200-2000) from gravel emery papers, cleaned $\&$ washed via bi-distilled water and acetone for removing greases. Applicable solution had been $1.0 \mathrm{M} \mathrm{HCl}$, which watery from $\mathrm{HCl}(37 \%)$.

\subsection{Chemicals}

\subsubsection{Plant extract preparation}

Chicoriumintybus plant was purchased from the local market and ground into a fine powder to give $200 \mathrm{~g}$ of powdered materials which extracted separately by soaking in $70 \%$ methanol $(300 \mathrm{ml})$ for $48 \mathrm{~h}$ at room temperature. Then the methanolic extract of the sample was concentrated to nearly dryness under reduced pressure by using the rotary evaporator at $45^{\circ} \mathrm{C}$ to achieve the crude methanolic extract which kept for further investigation.

Table 1. Structure of the main components and formulas and molecular weights of Chicoriumintybus extract.

\begin{tabular}{|l|l|l|l|}
\hline $\begin{array}{c}\text { Chicoriumintybus } \\
\text { extract }\end{array}$ & Structure of main components & Formula & $\begin{array}{c}\text { Mol. } \\
\text { Wt. }\end{array}$ \\
\hline 1 & & & \\
\hline 2 & &
\end{tabular}


The present investigation had been carried out utilizing the plant, namely Chicoriumintybus.

The samples had been purchased from the local market and the Chicoriumintybus extract stock solution $(1000 \mathrm{ppm})$ had been utilized for preparing the required doses by attenuation via bi-distilled water. Chicoriumintybus extract doses range had been between 50 to $300 \mathrm{ppm}$ (D. Mares et al; 2005).

\subsubsection{Solutions}

a. The applicable solution had been $1.0 \mathrm{M} \mathrm{HCl}$ which designed by attenuation of analytical grade $\mathrm{HCl}(37 \%)$ via bi-distilled water. The doses range of the tested green inhibitor had been between 50 to $300 \mathrm{ppm}$

b. Potassium iodide solution (KI) had been prepared with 1 X10 $10^{-2} \mathrm{M}$ with analytical grade for synergistic effect.

\subsection{Measurement techniques}

\subsubsection{Weight loss method (WL)}

WL had been a suitable and widespread procedure to estimate the corrosion inhibitor performance within acid media. The carefully glossed MS samples initial weights had been recorded earlier than inundation into $100 \mathrm{ml}$ of $1.0 \mathrm{M}$ $\mathrm{HCl}$ solution in the existence and nonexistence of various Chicoriumintybus extract doses which are between 50-300 ppm.

The total inundation time had been $3 \mathrm{hr}$ and the experiments have been conducted at various temperatures between 298 and 328 K. Each 30 minutes MS samples had been eliminated from the applicable solution, cleaned \& washed with bi-distilled water, after that dehydrated with the air gently and the mass had been calculated again. ML tests had been carried out three times and the average ML had been calculated. Each MS sample's mass had been recorded before and after inundation via 4-Digits laboratory electronic analytical balance.

The $(\theta)$ and (IE \%) had been computed via the subsequent eq. (1):

$\% \mathrm{IE}=\theta \times 100=\left[1-\left(\Delta \mathrm{W}_{\mathrm{inh}} / \Delta \mathrm{W}_{\text {free }}\right)\right] \times 100$

Where, $\Delta \mathrm{W}_{\text {inh }}$ and $\Delta \mathrm{W}_{\text {free }}$ had been the metal mass losses per unit area in existence and nonexistence of plant extract, correspondingly at a given time period and temperature.

\subsubsection{Electrochemical techniques}

Electrochemical measurements, involving OCP, PP, EIS and EFM tests had been used. The electrochemical tests had been made via a Gamry three-electrode cell gathering at $25^{\circ} \mathrm{C}$. The working electrode (WE) had been MS of $1.0 \mathrm{~cm}^{2}$, auxiliary electrode had been platinum electrode and reference electrode had been saturated calomel electrode (SCE). The WE had been scraped with various grades of gravel emery papers, cleaned \& washed via bi-distilled water and acetone for removing grease after that dried between two filter papers.

All experiments had been achieved for metal samples in $100 \mathrm{ml}$ of $0.1 \mathrm{M} \mathrm{HCl}$ in existence and nonexistence of plant extract doses at room temperature. Electrochemical tests had been achieved via Gamry Instrument (PCI4/750) Potentiostat/Galvanostat/ZRA, which involved a Gamry framework system derived from the ESA 400. Gamry applications involve DC105 software for potentiodynamic polarization, EIS 300 software for electrochemical impedance spectroscopy, and EFM 140 software for electrochemical frequency modulation tests using a computer in order to gain data

\subsubsection{Open circuit potential (OCP)}

In electrochemical experiments, working electrode had been examined like a timer function for the period of 10 minutes. This time requisite to achieve steady state and gained $(\mathrm{OCP})$ value.

\subsubsection{Potentiodynamic polarization (PP)}

Tafel curves had been gained potentiodynamically in a range of -0.1 to $0.2 \mathrm{~V}$ and inspect rate will be $1.0 \mathrm{mVs}^{-1}$, via the Stern-Geary equation, the linear polarization plot steps had been replaced to obtain corrosion current [24].
The IE $\%$ and $(\theta)$ had been computed via the subsequent eq. 2

$\% \mathrm{IE}=\theta \times 100=\left[1-\left(\mathrm{i}_{\text {inh }} / \mathrm{i}_{\text {free }}\right)\right] \times 100$

Where, $i_{\text {free }}$ and $i_{\text {inh }}$ are the corrosion current densities of uninhibited and inhibited solution, correspondingly.

\subsubsection{Electrochemical impedance spectroscopy (EIS)}

EIS had been conducted via an open-circuit potential (OCP) within the frequency range of $(1 \mathrm{~Hz}$ to $100 \mathrm{kHz})$ at an amplitude of $10 \mathrm{mV}$. Electrochemical functions, for example $\mathrm{R}_{\mathrm{ct}}$ and $\mathrm{C}_{\mathrm{dl}}$ values had been obtained and IE \% had been computed from charge transfer resistance $\left(R_{\mathrm{ct}}\right)$ gained from the real $\left(\mathrm{Z}^{\prime}\right)$ vs. imaginary (Z") plot. The impedance plots had been designed in Nyquist and Bode representation. IE \% and $(\theta)$ had been obtained from the EIS measurements via the subsequent eq. 3 :

$\% \mathrm{IE}=\theta \times 100=\left[1-\left(\mathrm{R}_{\mathrm{ct}}^{\mathrm{o}} / \mathrm{R}_{\mathrm{ct}}\right)\right] \times 100$

Where $R_{c t}$ and $R_{c t}^{o}$ are the charge transfer resistance in existence and nonexistence of the applicable extract inhibitor, correspondingly.

\subsubsection{Electrochemical frequency modulation (EFM)}

EFM had been utilized as a novel method to estimate the corrosion rate [25]. EFM tests had been achieved via potential disturbance signal through amplitude of $10 \mathrm{mV}$ through two sine signals of 2 and $5 \mathrm{~Hz}$. The inter-modulation spectra had been included current responses allocated for harmony and inter-modulation current peaks. The higher peaks had been utilized to compute the corrosion current density $\left(i_{\text {corr }}\right)$, the Tafel slopes $\left(\beta_{\mathrm{a}}\right.$ and $\left.\beta_{\mathrm{c}}\right)$ and the causality factors $\mathrm{CF} 2 \&$ CF3 [26].

\subsection{Surface morphology}

\subsubsection{Scanning electron microscopy (SEM)}

Inspection of MS sample's surface in the existence and nonexistence of the maximum dose of the Chicoriumintybus extract $(300 \mathrm{ppm})$ which had been inundated for $24 \mathrm{~h}$ at room temperature had been studied via (JEOL JSM-5500, JAPAN) model.

\subsubsection{Atomic force microscopy (AFM)}

AFM had been a positive tool to contact the fine points of corrosion process at the molecular level. In order to take the surface micrographs, the designed MS samples had been inundated in $1.0 \mathrm{M} \mathrm{HCl}$ in the existence and nonexistence of Chicoriumintybus extract. After 24 hour the samples were removed from applicable solution, cleaned \& washed with bi-distilled water and dried. Thus obtained samples were analyzed by used in a Pico SPM2100 AFM apparatus working in contact mode in air at Nanotechnology Laboratory, Faculty of Engineering, Mansoura University.

\subsubsection{Attenuated total reflection-infrared spectroscopy (ATR-IR)}

The MS sample's had been inundated in $100 \mathrm{ml}$ of $1.0 \mathrm{M} \mathrm{HCl}$ in the existence and nonexistence of $300 \mathrm{ppm}$ of Chicoriumintybus extract at room temperature. After $24 \mathrm{~h}$, the sample's had been eliminated and dried by air. Then, the MS sample's surface coating had carefully scratched and the gotten samples utilized to the ATR-IR spectrum test. IR Affinity (Perkin-Elmer) spectrophotometer had been utilized in order to gain ATR-IR data define the composition of the corrosion product obtained on the MS surface.

\section{RESULTS AND DISCUSSION}

\subsection{Weight loss method (WL)}

WL-time curves of MS in applicable solution 1.0 M HCl have been determined in the existence and nonexistence of various Chicoriumintybus extract doses, which has been shown in Figure 1. The gained corrosion parameters data have been reported in Table 2, from which we have been finding that IE\% raises with rising Chicoriumintybus extract doses and raises with rising temperature. Lowering in corrosion rate (CR) by rising Chicoriumintybus extract doses is as a result of the fact that the metal surface coverage $(\theta)$ become larger via the adsorption of inhibitor molecules [27]. 
The reduce in CR possibly with rising in temperature via the adsorption rate of Chicoriumintybus extract on the MS surface has been raised at higher temperatures [28].

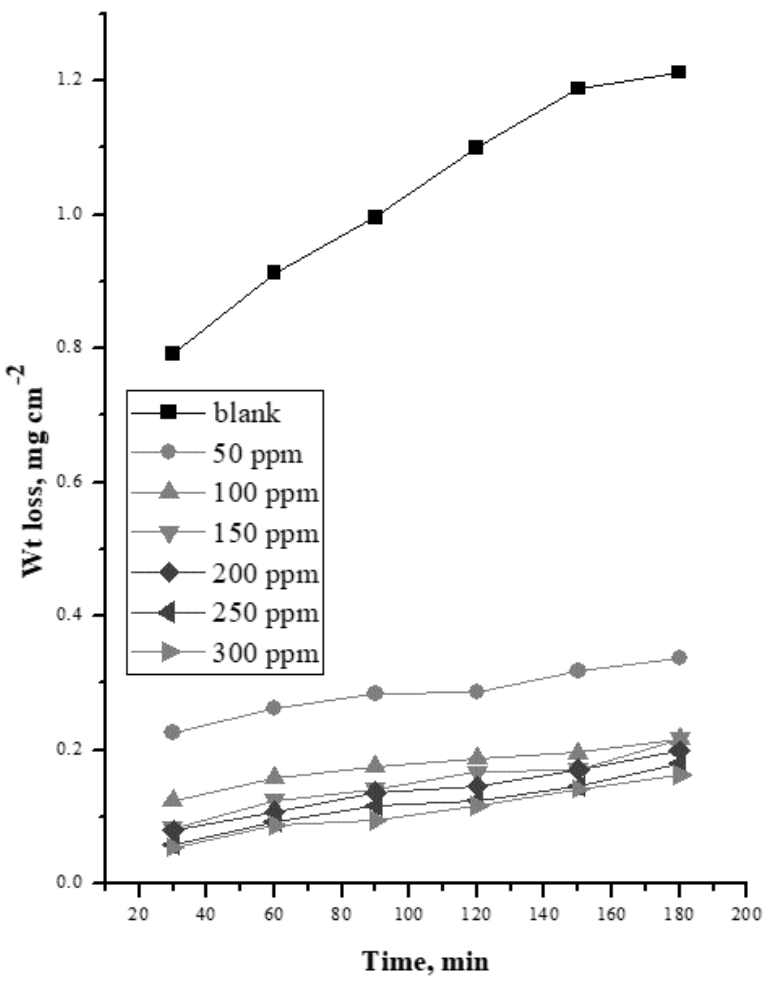

Figure 1. WL vs. time plot for corrosion of MS in $1.0 \mathrm{M} \mathrm{HCl}$ in the existence and nonexistence of different Chicoriumintybus extract doses at $25^{\circ} \mathrm{C}$.

Table 2. WL measurements Data for MS in $1.0 \mathrm{M} \mathrm{HCl}$ in the existence and nonexistence of different Chicoriumintybus extract doses at $25-55^{\circ} \mathrm{C}$.

\begin{tabular}{|c|c|c|c|c|c|}
\hline Conc., ppm & Temp., ${ }^{\circ} \mathbf{C}$ & Wt. loss, (mg) & C.R., $\mathrm{mg} \mathrm{cm}^{-2} \min ^{-1}$ & $\%$ IE & $\Theta$ \\
\hline \multirow{4}{*}{50} & 25 & 6.9 & 0.0020 & 73.8 & 0.738 \\
\hline & 35 & 8.7 & 0.0030 & 81.6 & 0.816 \\
\hline & 45 & 8.8 & 0.0030 & 83.5 & 0.835 \\
\hline & 55 & 11.9 & 0.0040 & 84.9 & 0.849 \\
\hline \multirow{4}{*}{100} & 25 & 4.5 & 0.0020 & 82.9 & 0.829 \\
\hline & 35 & 7.6 & 0.0030 & 83.9 & 0.839 \\
\hline & 45 & 7.8 & 0.0030 & 85.4 & 0.854 \\
\hline & 55 & 10 & 0.0030 & 87.1 & 0.871 \\
\hline \multirow{4}{*}{150} & 25 & 4.25 & 0.0015 & 83.9 & 0.839 \\
\hline & 35 & 7.2 & 0.0025 & 84.8 & 0.848 \\
\hline & 45 & 7.1 & 0.0025 & 86.7 & 0.867 \\
\hline & 55 & 8.6 & 0.0030 & 89.0 & 0.890 \\
\hline \multirow{4}{*}{200} & 25 & 3.9 & 0.0014 & 85.3 & 0.853 \\
\hline & 35 & 6.3 & 0.0022 & 86.7 & 0.867 \\
\hline & 45 & 6 & 0.0021 & 88.7 & 0.887 \\
\hline & 55 & 7.8 & 0.0027 & 90.0 & 0.900 \\
\hline \multirow{4}{*}{250} & 25 & 3.25 & 0.0011 & 87.7 & 0.877 \\
\hline & 35 & 5.4 & 0.0019 & 88.6 & 0.886 \\
\hline & 45 & 5.9 & 0.0020 & 88.9 & 0.889 \\
\hline & 55 & 7.5 & 0.0026 & 90.4 & 0.904 \\
\hline \multirow{4}{*}{300} & 25 & 3 & 0.0010 & 88.6 & 0.886 \\
\hline & 35 & 5 & 0.0017 & 89.3 & 0.893 \\
\hline & 45 & 5.7 & 0.0020 & 89.4 & 0.894 \\
\hline & 55 & 6.6 & 0.0023 & 91.5 & 0.915 \\
\hline
\end{tabular}

\subsection{Synergistic effect}

$\mathrm{KI}$ anion is found to enhance the inhibitive effect of the Chicoriumintybus extract in acidic solutions [29]. In the present stud, the influence of this anion I on the inhibitive performance of the Chicoriumintybus extract has been studied using weight loss method.

Figure 2, represent the weight loss-time curves for mild-steel dissolution in $1.0 \mathrm{M} \mathrm{HCl}$ for various concentrations of the Chicoriumintybus extract and at specific concentration $\left(1 \mathrm{X} 10^{-2} \mathrm{M}\right)$ of this salt. The values of inhibition efficiency (\%IE) for various concentrations of inhibitor in the presence of specific concentrations of potassium iodide are given in Table 3.

The synergistic inhibition effect was evaluated using a parameter, $\mathrm{S}_{\theta}$, obtained from the surface coverage values $(\theta)$ of the anion, cation and both. Aramaki and Hackerman, calculated the synergism parameter $S_{\theta}$ using the following equation:

$\mathrm{S}_{\theta}=1-\theta_{1+2} / 1-\theta_{1+2}^{\prime}$

Where: $\theta_{1+2}=\left(\theta_{1}+\theta_{2}\right)-\left(\theta_{1} \theta_{2}\right)$;

$\theta_{1}=$ surface coverage by anion;

$\theta_{2}=$ surface coverage by cation;

$\theta^{\prime}{ }_{1+2}=$ measured surface coverage by both the anion and cation.

We calculate synergism parameters from the above equation. The plot of the synergism parameter $\left(\mathrm{S}_{\theta}\right)$ against various concentrations of the investigated extract are given in Figure 3 and the corresponding values are shown in Table 3. As can be seen from Table 4 these values nearly equal to unity, which suggests that the enhanced inhibition efficiencies caused by the addition of iodide, to plant extract is due mainly to the synergistic effect.

Finally; It is observed that the inhibition efficiency (\%IE) of the inhibitor increases with increasing concentration of inhibitors due to synergistic effects as reported by Cahskan and Bilgic [30]. The synergistic effect of the anions Ihave been observed, this effect depends on the type of anion [31]. Adsorption of the extract at the mild steel/solution interface occurs through chemical adsorption via electron rich centers, i.e. benzene ring through its $\pi$-electrons and nitrogen atoms through its lone pair of electrons by donation of electrons to the empty dorbital of the metal. It is known that $\mathrm{I}^{-}$anions have strong interactions with mild steel surfaces owing to chemisorption. The strong chemisorption of $\mathrm{I}^{-}$anions on the metal surface is responsible for the synergistic effect of iodide anions in combination with cation of the inhibitor. The cations are then adsorbed by coulombic attraction on the metal surface where iodide anions are already adsorbed by chemisorption. Stabilization of adsorbed iodide anions with cations leads to greater surface coverage and therefore greater inhibition. From the previous results, it is known that KI could be considered as one of the effective anions for synergistic action within the investigated inhibitor.

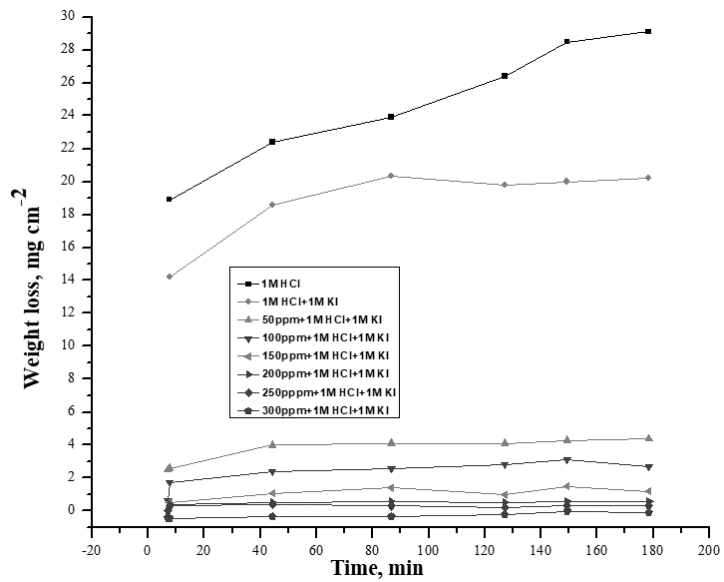

Figure 2. Weight loss-time curve for mild steel dissolution in $1.0 \mathrm{M} \mathrm{HCl}$ in the existence and nonexistence of $1 \times 10^{-2} \mathrm{M} \mathrm{KI}$ in the presence of different concentrations of Chicoriumintybus extract at $25^{\circ} \mathrm{C}$. 


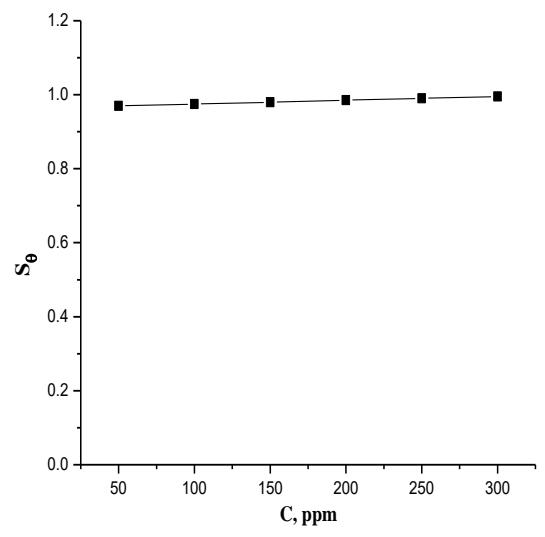

Figure 3. plot of synergism parameter $\mathrm{S}_{\theta} v s$. the concentration of Chicoriumintybus extract in absence and presence of $1 \times 10^{-2} \mathrm{M} \mathrm{KI}$ at $25^{\circ} \mathrm{C}$.

Table 3. Inhibition efficiencies Values (\%IE) of different concentrations of

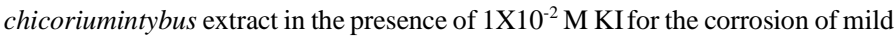
steel in $1.0 \mathrm{M} \mathrm{HCl}$ at $25^{\circ} \mathrm{C}$.

\begin{tabular}{|c|c|c|}
\hline \multirow{2}{*}{ Conc., ppm } & \multicolumn{2}{|c|}{ Inhibition efficiency (\%IE) } \\
\cline { 2 - 3 } & Chicoriumintybus & Chicoriumintybus with KI \\
\hline 50 & 73.8 & 84.4 \\
\hline 100 & 82.9 & 95.8 \\
\hline 150 & 83.9 & 97.3 \\
\hline 200 & 85.3 & 98.1 \\
\hline 250 & 87.7 & 99.2 \\
\hline 300 & 88.6 & 99.6 \\
\hline
\end{tabular}

Table 4. Synergism parameter $\left(\mathrm{S}_{\theta}\right)$ for various concentrations of chicoriumintybus extract in the presence of $1 \mathrm{X}^{-2} \mathrm{M} \mathrm{KI}$.

\begin{tabular}{|c|c|}
\hline \multirow{2}{*}{ Conc., $\mathbf{p p m}$} & Synergism parameter $\left(\mathbf{S}_{\boldsymbol{\theta}}\right)$ \\
\cline { 2 - 2 } & Chicoriumintybus \\
\hline 50 & 0.970 \\
\hline 100 & 0.975 \\
\hline 150 & 0.980 \\
\hline 200 & 0.985 \\
\hline 250 & 0.990 \\
\hline 300 & 0.995 \\
\hline
\end{tabular}

\subsection{Electrochemical techniques}

\subsubsection{Open circuit potential (OCP)}

Figure 4, has been the indication of the influence of different concentrations of Chicoriumintybus extract on the $\mathrm{E}_{\mathrm{OC}}$ variety of mild steel with time in $1.0 \mathrm{M} \mathrm{HCl}$ solution at $25^{\circ} \mathrm{C}$. Steady-state data of the $\mathrm{E}_{\mathrm{OC}}$ are larger negative than the inundation potential $\left(\mathrm{E}_{\mathrm{OC}}\right.$ at $\mathrm{t}=0$ ), indicating so as previous to the steady state condition has been achieved the pre-inundation, air oxide film formed has to break up [32]. This steady state potential $\left(\mathrm{E}_{\text {corr.) }}\right.$ rapidly obtained (later than 10 min of inundation), be in contact to the bare metal free corrosion [33]. It has been noticeable that $\left(\mathrm{E}_{\mathrm{corr} .}\right)$ shifts to larger negative data without the alteration general feature of E/t plot. On the other hand upon rising the concentration of Chicoriumintybus extract.

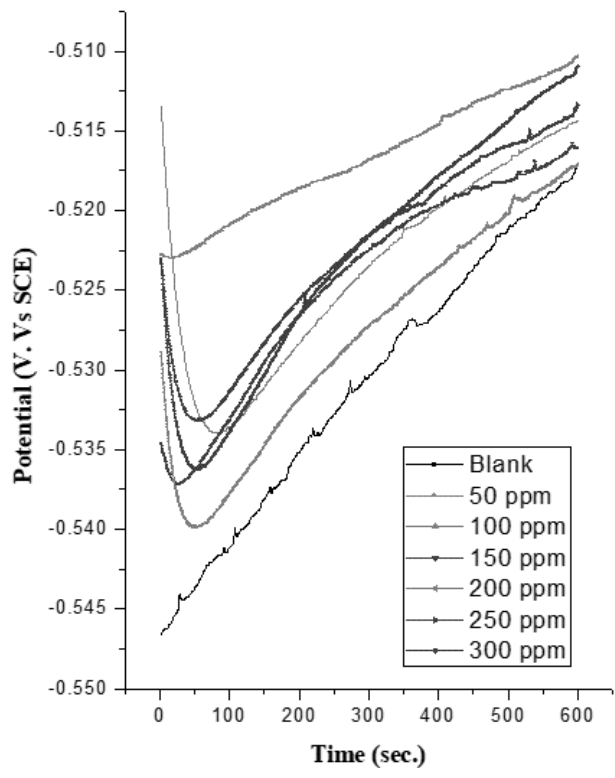

Figure 4. Variation of open circuit potential $\left(\mathrm{E}_{\mathrm{OC}}\right)$ as a parameter of time record for mild steel in $1.0 \mathrm{M} \mathrm{HCl}$ in the existence and non existence of different Chicoriumintybus extract doses at $25^{\circ} \mathrm{C}$.

Firstly, the $\mathrm{E}_{\mathrm{OC}}$ has been proceeded to lower negative data, achieving a maximum one. After assuring time relying on the Chicoriumintybus extract doses, the potential decrease and arrive a reasonably steady value. These data have been elucidated that two counter- appearing processes happened, the initial one has been a creation of protective adsorbed film on the electrode surface, in addition to a result delayed-action corrosion takes place which moving $\mathrm{E}_{\mathrm{OC}}$ values towards more noble data. Corrosion has been occurring on the next one, which has been made potential back towards among these two counter performing operations can possibly elucidate semblance of an arrest or peak in $\mathrm{E}_{\mathrm{OC}}$ vs. time plot as presented in Figure 4. The steady-state potential proceed towards larger negative data with rising the Chicoriumintybus extract doses. Initially, $E_{O C}$ has been shifted to lower negative values (as a result of corrosion inhibition) accomplishing high one. In addition to, after a suitable time the potential has been reduced to achieve a reasonably steady value (as a result of metal dissolution), which effect the corrosion potential steady state proceeding towards larger negative value. These data illuminate that the Chicoriumintybus extract is an efficiency corrosion inhibitor.

\subsubsection{Potentiodynamic polarization (PP)}

PP measurements have been applied to discuss the influence of Chicoriumintybus extract on both anodic and cathodic processes occurring in the system. From Table 5, It has been clear that $\mathrm{i}_{\text {corr }}$ data are reducing with rising inhibitor doses, which obviously illustrates corrosion inhibition IE\%. From Figure 5, it has been obvious that Chicoriumintybus extract delay both anodic and cathodic processes, and also supported by the gained data in Table 3. Both $\beta_{\mathrm{a}}$ and $\beta_{\mathrm{c}}$ data have been changed, in other hand, there has been no normal displacement pattern in $E_{\text {corr }}$ data which have been illustrated that Chicoriumintybus extract act as a mixed type inhibitor. Via Ferreira and others [34], if the corrosion potential displacement has been larger than $85 \mathrm{mV}$ relating to the corrosion potential of blank, Chicoriumintybus extract may be act as anodic or cathodic type.

Table 5. $\mathrm{PP}$ values of $\mathrm{MS}$ in $1.0 \mathrm{M} \mathrm{HCl}$ in existence and nonexistence of different Chicoriumintybus extract doses at $25^{\circ} \mathrm{C}$.

\begin{tabular}{|c|c|c|c|c|c|c|c|}
\hline Conc., ppm & $\begin{array}{c}-\mathbf{E}_{\text {corr, }} \\
\text { mV vs SCE }\end{array}$ & $\begin{array}{c}\mathbf{i}_{\text {corr, }} \\
\mu \mathrm{A} \mathrm{cm}^{-2}\end{array}$ & $\begin{array}{c}\beta_{\mathrm{c}} \\
\mathrm{mV} \operatorname{dec}^{-1}\end{array}$ & $\begin{array}{c}\beta_{\mathrm{a}} \\
\mathrm{mV} \operatorname{dec}^{-1}\end{array}$ & $\begin{array}{l}\text { C.R, } \\
\text { mpy }\end{array}$ & IE\% & $\boldsymbol{\theta}$ \\
\hline 50 & 509 & 284 & 142 & 91 & 129.8 & 80.5 & 0.805 \\
\hline 150 & 511 & 244 & 131 & 87 & 111.3 & 83.3 & 0.833 \\
\hline 200 & 510 & 239 & 133 & 89 & 109.3 & 83.6 & 0.836 \\
\hline 250 & 506 & 183 & 130 & 85 & 83.8 & 87.5 & 0.875 \\
\hline 300 & 496 & 147 & 132 & 77 & 67.0 & 89.9 & 0.899 \\
\hline
\end{tabular}




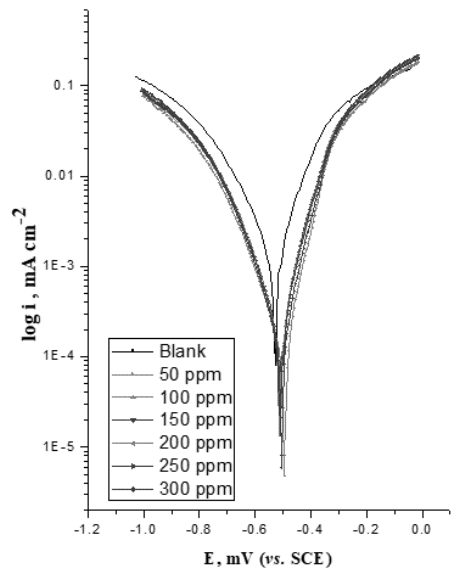

Figure 5. PP curves of the corrosion of $\mathrm{MS}$ in $1.0 \mathrm{M} \mathrm{HCl}$ in the existence and nonexistence of different Chicoriumintybus extract doses at $25^{\circ} \mathrm{C}$.

\subsubsection{Electrochemical impedance spectroscopy (EIS)}

EIS has been an embedded and influential tool in corrosion measurements. The electrochemical process happening at the OCP has been studied via EIS to facilitate gaining a mechanistic conception, electrode kinetics, MS surface properties of corrosion in the existence of Chicoriumintybus extract [35]. Figure 6 , has been illustrated Nyquist plots, which included a semicircle; the diameter has been larger by rising the Chicoriumintybus extract doses. This has been denoted that inhibition efficiency is directly proportional to the Chicoriumintybus extract doses. The capacitive loop shapes have been shown that the corrosion process has been largely charge transfer restriction [36]. The rising in charge transfer resistance $\left(\mathrm{R}_{\mathrm{ct}}\right)$ via Chicoriumintybus extract doses denotes significant inhibitor surface coverage and surface strong bonding. The Nyquist plots have been evaluated by way of the equivalent circuit shown in Figure 7, which has been commonly utilized in order to explain given EIS data. The $\mathrm{R}_{\mathrm{ct}}$ data have been raised and double layer capacitance $\left(\mathrm{C}_{\mathrm{dl}}\right)$ data lowered with rising in Chicoriumintybus extract doses, which has been most likely via lowering the local dielectric constant or rising electrical double layer thickness. This recommends that Chicoriumintybus extract strongly adsorbed on the MS surface [37]. Rising in $\mathrm{R}_{\mathrm{ct}}$ data and lowering in the $\mathrm{C}_{\mathrm{dl}}$ data causes an increase in the inhibition efficiency IE\%. Data have been gained for MS in $1.0 \mathrm{M} \mathrm{HCl}$ solution in the existence and nonexistence of different Chicoriumintybus extract doses. while Nyquist plots data gained for the inhibitor present, which are exhibiting a circle, such manner has been attributed for solid electrodes and is commonly shared to a frequency dispersion creating from the surface irregularity. The $\mathrm{C}_{\mathrm{dl}}$ data have been gained from subsequent eq. 4 :

$$
\mathrm{C}_{\mathrm{dl}}=1 / 2 \pi R_{c \mathrm{t}} f_{m_{\mathrm{ax}}}
$$

Where, $f_{\max }$ symbolizes the frequency at which imaginary data arrives a maximum at Nyquist plots. In Bode plots which are shown in Figure 6, the larger frequency border refers to the solution resistance $R_{S}(\Omega)$, however the minimum frequency border refers to $\left(\mathrm{R}_{\mathrm{ct}}+\mathrm{R}_{\mathrm{s}}\right)$. The lower frequency illustrates the charge transfer reaction kinetic response [38]. The corrosion parameters of impedance tests have been shown in Table 6 . The gained data have been illustrated that $R_{c t}$ values raises with rising the Chicoriumintybus extract doses, which drives to IE\% have been increased and double layer capacitance $\left(\mathrm{C}_{\mathrm{dl}}\right)$ data have been reduced in the existence of the inhibitor.
The lowering in $\mathrm{C}_{\mathrm{dl}}$ due to a reduce in local dielectric constant and/or arising in double layer thickness. therefore, it has been reasonable to reduce functions presented in inhibitor extract via the metal- acid interface adsorption [39]. It is clear that there has been a good congruence between the two dissimilar electrochemical measurements, due to that the same trend of inhibition of the Chicoriumintybus extract.
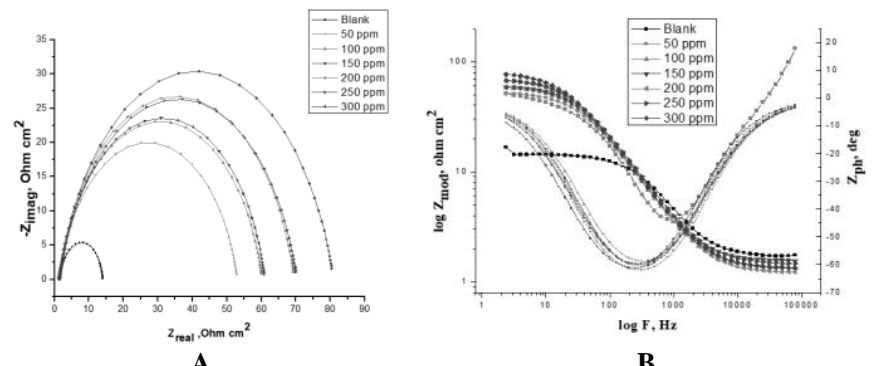

B

Figure 6. The Nyquist (a) and Bode (b) curves for the corrosion of MS in 1.0 $\mathrm{M} \mathrm{HCl}$ in the existence and nonexistence of different Chicoriumintybus extract doses at $25^{\circ} \mathrm{C}$.

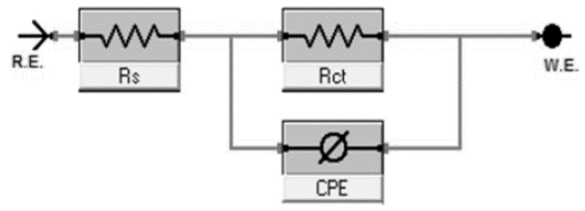

Figure 7. Equivalent circuit as a model for impedance data for MS in $1.0 \mathrm{M}$ $\mathrm{HCl}$ solution.

Table 6. EIS parameters for corrosion of MS in $1.0 \mathrm{M} \mathrm{HCl}$ in the existence and nonexistence of the different Chicoriumintybus extract doses at $25^{\circ} \mathrm{C}$.

\begin{tabular}{|c|c|c|c|c|}
\hline Conc., $\mathbf{p p m}$ & $\mathbf{R}_{\mathbf{c t}}, \mathbf{\Omega} \mathbf{~ c m}^{\mathbf{2}}$ & $\mathbf{C}_{\mathbf{d l}}, \boldsymbol{\mu} \mathbf{F c m}^{-\mathbf{2}}$ & $\mathbf{I E} \%$ & $\boldsymbol{\Theta}$ \\
\hline Blank & 12.3 & 47 & ---- & ---- \\
\hline 50 & 51.8 & 38 & 76.2 & 0.762 \\
\hline 100 & 58.9 & 35 & 79.1 & 0.791 \\
\hline 150 & 59.5 & 32 & 79.3 & 0.793 \\
\hline 200 & 68.4 & 29 & 82.0 & 0.820 \\
\hline 250 & 68.8 & 25 & 82.1 & 0.821 \\
\hline 300 & 79.6 & 20 & 84.5 & 0.845 \\
\hline
\end{tabular}

\subsubsection{Electrochemical frequency modulation (EFM).}

The current-frequency spectral chart gained from EFM tests in the existence and nonexistence of different Chicoriumintybus extract doses have been illustrated in Figure 8. The spectra have been analyzed to calculate $i_{\text {corr }}, \beta_{\mathrm{a}}, \beta_{\mathrm{c}}$ and the causality factors (CF-2 and CF-3) which have been reported in Table 7. From this Table We noticed that $\mathrm{i}_{\text {corr }}$ has been reduced with rising Chicoriumintybus extract doses and the IE\% has been raised via rising the extract doses. The change in magnitudes of $\beta_{\mathrm{a}}$ and $\beta_{\mathrm{c}}$ values was also small, indicating that the existence of extract doesn't adjust the corrosion mechanism. The causality factors CF-2 and CF-3 which have been gained are closed to theoretical values of 2 and 3 correspondingly, showing that the gained values have been verified and good quality [40].

Table 7. Electrochemical kinetic parameters gained via EFM test for MS in $1.0 \mathrm{M} \mathrm{HCl}$ in the existence and nonexistence of the different Chicoriumintybus extract doses at $25^{\circ} \mathrm{C}$.

\begin{tabular}{|c|c|c|c|c|c|c|c|c|}
\hline Conc., pm & $\mathbf{i}_{\text {corr }}, \mu \mathbf{A c m}^{-2}$ & $\beta_{c}, m^{\prime} d e c^{-1}$ & $\beta_{a}, \mathrm{mVdec}^{-1}$ & CF-2 & CF-3 & C.R, mpy & IE\% & $\theta$ \\
\hline Blank & 528 & 1460 & 169 & 74 & 8.6 & ---- & -ב--- & Blank \\
\hline 50 & 304 & 98 & 93 & 1.9 & 2.8 & 139.0 & 78.6 & 0.786 \\
\hline 100 & 295 & 100 & 92 & 1.9 & 3.2 & 135.0 & 79.2 & 0.792 \\
\hline 150 & 274 & 106 & 89 & 1.9 & 3.1 & 125.3 & 80.8 & 0.808 \\
\hline 200 & 254 & 98 & 83 & 1.9 & 2.8 & 116.2 & 82.2 & 0.822 \\
\hline 250 & 235 & 95 & 95 & 1.9 & 2.7 & 107.5 & 83.5 & 0.835 \\
\hline 300 & 216 & 106 & 85 & 1.9 & 2.8 & 98.6 & 84.8 & 0.848 \\
\hline
\end{tabular}



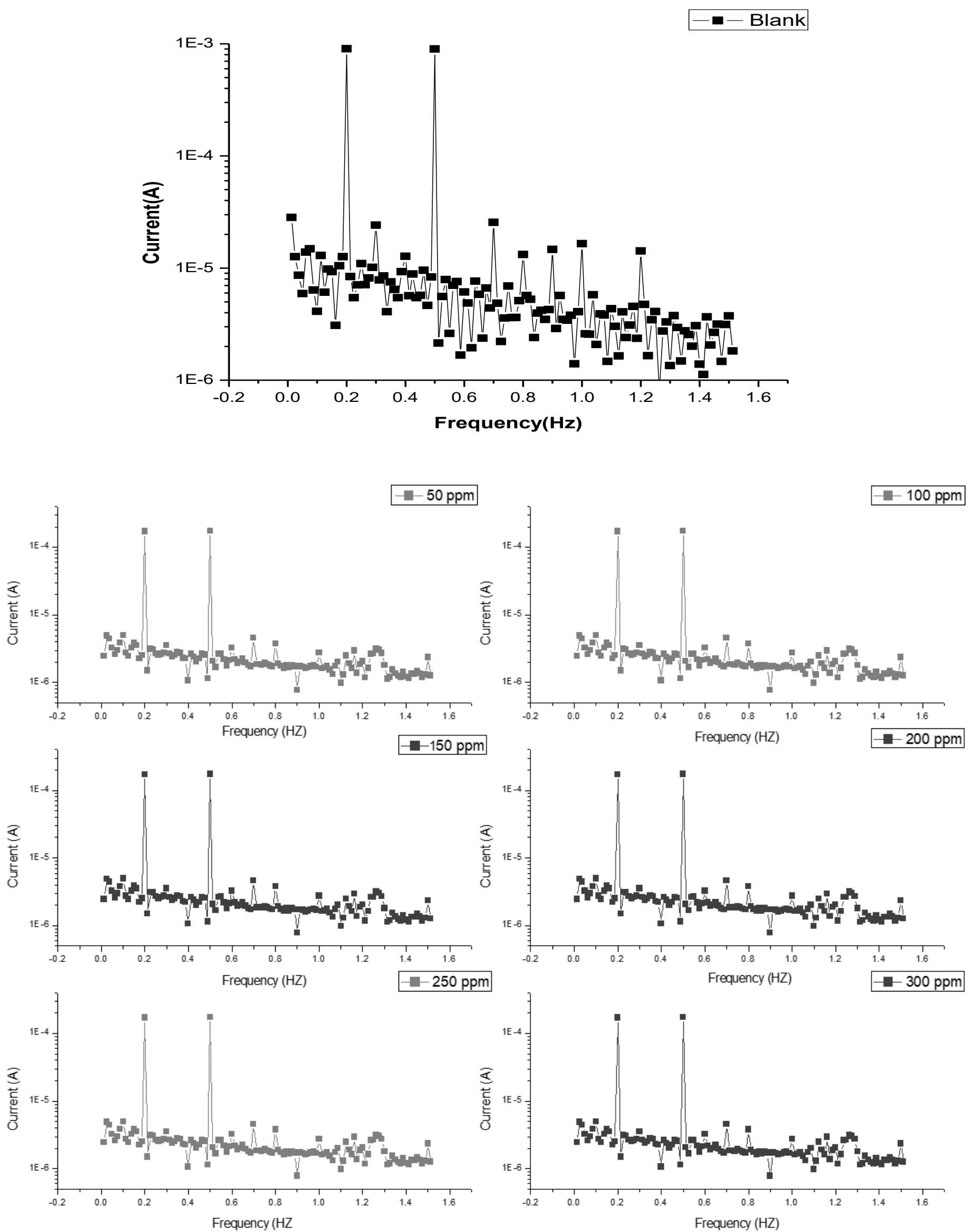

Figure 8. Inter-modulation spectrum for the corrosion of $\mathrm{MS}$ in $1.0 \mathrm{M} \mathrm{HCl}$ in the existence and nonexistence of different Chicoriumintybus extract doses at $25^{\circ} \mathrm{C}$. 


\subsection{Adsorption isotherms}

Corrosion inhibitors influence is reliant on MS surface adsorption modes. while the interaction forces between MS surface and water molecules has been minor than another one between the MS surface and the inhibitor compound, a replacement adsorption process may be created and water molecules adsorbed on the MS surface, $\left(\mathrm{H}_{2} \mathrm{O}\right)_{\text {ads }}$ molecules have been substituted by inhibitor molecules in the aqueous phase (inhibitor ${ }_{\text {aq }}$ ).

$$
\mathrm{xH}_{2} \mathrm{O}_{\text {ads }}+\text { Inhibitor }_{\text {sol }} \leftrightarrow \text { Inhibitor }_{\text {ads }}+\mathrm{xH}_{2} \mathrm{O}
$$

Where $\mathrm{x}$ characterizes the size ratio, the number of water molecules replaced with one inhibitor molecule. The inhibitor adsorption process may either happen physically or chemically on a corroded MS surface, wherever the physisorbed molecules delay metal dissolution by blocking the cathodic reaction, even as chemisorbed molecules block the anodic reaction via lowering the ingrained reactivity on the metal adsorption sites.

Essential knowledge on the interaction between metal surface \& plant extract has been supplied via the adsorption isotherms [41]. Therefore, in order to collect most knowledge about the adsorption mode of Chicoriumintybus extract on the MS surface in $1.0 \mathrm{M} \mathrm{HCl}$ at various temperatures. Efforts have been prepared to fit experimental data by a number of adsorption isotherms as Langmuir, Temkin, Freundlich, Bockris-Swinkles and Flory-Huggins isotherms. On the other hand, the top fit has been resulted via Temkin isotherm, which has been in a good agreement with subsequent eq. (6):

$$
\operatorname{InK}_{\mathrm{ads}} \mathrm{C}=\mathrm{a} \theta
$$

Where $\mathrm{K}_{\mathrm{ads}}$, the adsorption reaction equilibrium constant, $\mathrm{C}$, the inhibitor concentration in the bulk of solution, (a) the interaction parameter and $(\theta)$ the surface coverage.

Plots of $\theta$ vs. $\log C$ for plant additives adsorption on the MS surface in $1.0 \mathrm{M}$ $\mathrm{HCl}$ acid at $25-55^{\circ} \mathrm{C}$ has been illustrated in Figure 9. The gained results create straight lines demonstrating that Temkin's isotherm has been available for applied systems.

$$
\begin{aligned}
& \left(\Delta \mathrm{G}_{\text {ads }}^{\circ}\right) \text { was calculated from subsequent eq. (7): } \\
& \Delta \mathrm{G}_{\text {ads }}^{\circ}=-\mathrm{RT} \ln 55.5 \mathrm{~K}_{\text {ads }}
\end{aligned}
$$

Where $\mathrm{R}$ is the gas constant and $\mathrm{T}$ is the absolute temperature. 55.5 value has been the water concentration in solution in mol $^{-1}$. To calculate heat of adsorption $\left(\Delta \mathrm{H}^{\circ}{ }_{\text {ads }}\right)$, a plot of $\log \Delta \mathrm{G}_{\text {ads }}^{\circ} \mathrm{vs}$. $\mathrm{T}$ was done Figure 10 . The intercept would be equal to $\Delta \mathrm{H}^{\circ}$ ads according to the subsequent equation:

$\Delta G_{\text {ads }}^{\circ}=\Delta \mathrm{H}_{\text {ads }}^{\circ}-\mathrm{T} \Delta \mathrm{S}_{\text {ads }}^{\circ}$

The adsorption entropy $\left(\Delta \mathrm{S}_{\text {ads }}^{\circ}\right)$, could be calculated from the previous equation and the data of $\left(\mathrm{K}_{\text {ads }}\right),\left(\Delta \mathrm{G}^{\circ}\right.$ ads $),\left(\Delta \mathrm{H}^{\circ}{ }_{\text {ads }}\right)$ and $\left(\Delta \mathrm{S}_{\text {ads }}^{\circ}\right)$ are reported in Table 8 . These data indicate that:

The adsorption entropy $\left(\Delta \mathrm{S}_{\text {ads }}^{\circ}\right.$, which obtained via the subsequent equation:

$\Delta G_{\text {ads }}^{\circ}=\Delta \mathrm{H}_{\text {ads }}^{\circ}-\mathrm{T} \Delta \mathrm{S}_{\mathrm{ads}}^{\circ}$

The data of $\left(\mathrm{K}_{\mathrm{ads}}\right),\left(\Delta \mathrm{G}_{\mathrm{ads}}^{\circ}\right),\left(\Delta \mathrm{H}_{\text {ads }}^{\circ}\right)$ and $\left(\Delta \mathrm{S}_{\text {ads }}^{\circ}\right)$ are reported in Table 8 . These data indicate that:

i. The values of $\mathrm{K}_{\mathrm{ads}}$ increase with rising in temperature. The detected reports indicated that $\mathrm{K}_{\text {ads }}$ obtained from the Temkin isotherm has been raised with temperature rising.

ii. $\Delta \mathrm{G}_{\text {ads }}^{\circ}$ have a negative sign, be a sign of the extract is spontaneously adsorbed on the metal surface [42].

iii. $\Delta \mathrm{G}_{\text {ads }}^{\circ}$ values has been found around $-40 \mathrm{~kJ} \mathrm{~mol}^{-1}$ referring that the adsorption nature for Chicoriumintybus extract in $1.0 \mathrm{M} \mathrm{HCl}$ has been chemical adsorption [43].

iv. $\Delta \mathrm{H}^{\circ}$ ads a positive sign, refer to that the extract adsorption process has been an endothermic process [44]

v. $\Delta \mathbf{S}_{\text {ads }}^{\circ}$ have positive values, has been frequently characteristic to endothermic adsorption process.

Generally, an endothermic process has been typically characteristic to chemisorption via electron transfer from inhibitor to metal surface in order to create co-ordination bond while exothermic adsorption process suggests either physisorption or chemisorption [42]. The lone pairs of electrons in estimated molecules can be interacted with vacant MS d-orbital in order to create chemisorbed film.

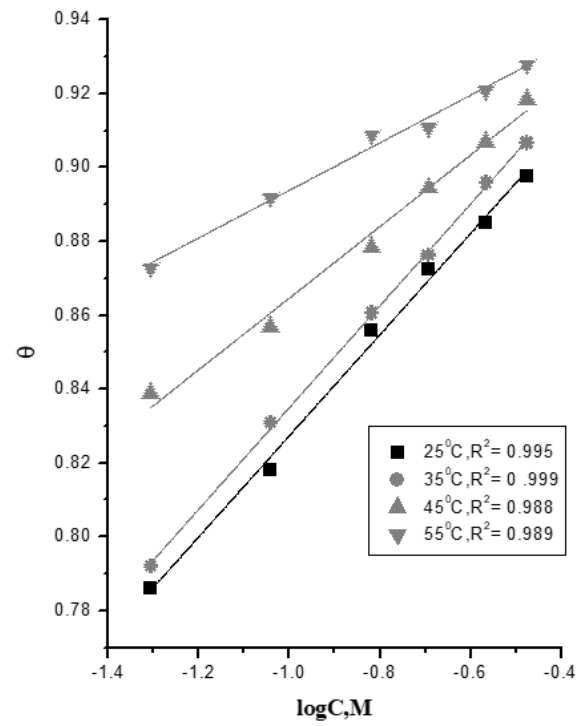

Figure 9. Temkin adsorption curves for MS in $1.0 \mathrm{M} \mathrm{HCl}$ with different

\begin{tabular}{|c|c|c|c|c|}
\hline Temp., ${ }^{\circ} \mathrm{C}$ & $\log \mathbf{K}_{\mathrm{ads}}, \mathbf{M}^{-1}$ & $\begin{array}{c}-\Delta \mathbf{G}^{\mathbf{o}}{ }^{a d s} \\
\mathbf{k J ~ m o l}{ }^{-1}\end{array}$ & $\begin{array}{c}\Delta \mathbf{H}^{0}{ }^{0}{ }^{2} \\
\mathrm{~kJ} \mathrm{~mol}^{-1}\end{array}$ & $\begin{array}{c}\Delta \mathbf{S}_{\text {ads }}^{o} \\
\mathbf{J ~ m o l}^{-1} \mathbf{K}^{-1}\end{array}$ \\
\hline 25 & 7.1 & 50.5 & \multirow{4}{*}{19.1} & 233.6 \\
\hline 35 & 9.2 & 64.5 & & 271.7 \\
\hline 45 & 11 & 77.6 & & 304.2 \\
\hline 55 & 11.1 & 80.6 & & 304.3 \\
\hline
\end{tabular}
Chicoriumintybus extract doses at different temperatures.

Table 8. Adsorption thermodynamic functions of the Chicoriumintybus extract on MS surface in $1.0 \mathrm{M} \mathrm{HCl}$ at different temperatures.

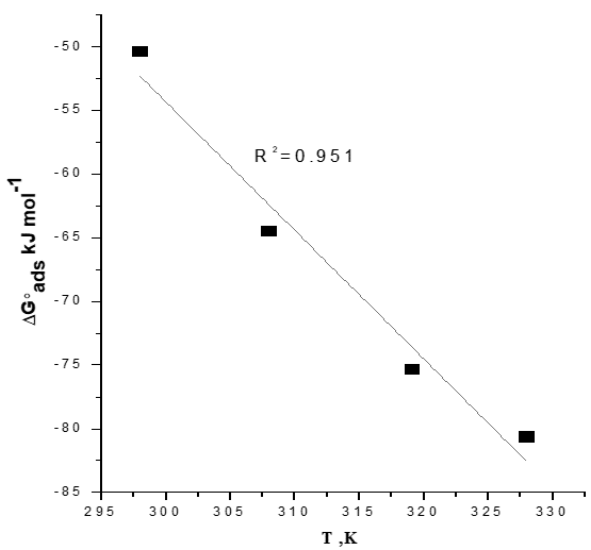

Figure 10. $\Delta \mathrm{G}_{\text {ads }}^{\circ}$ has been plotted $v s . \mathrm{T}(\mathrm{K})$ for the Chicoriumintybus extract.

\subsection{Kinetic-thermodynamic corrosion parameters}

Usually, chemisorption process has been a sign of the higher value of $E_{a}$ detected for free acid solution match up to the inhibited one. This may be clarified that the total corrosion process shift from exposed surface to adsorbed sites accounts for $E_{a}$ reducing at larger inhibition levels [45]. as well, lowering $E_{a}$ at higher temperatures may be correlated with rising inhibitor molecules adsorption onto the metal surface.

Table 9 illustrated that the $\mathrm{E}_{\mathrm{a}}$ data on the existence of the Chicoriumintybus extract are less than the blank solution one, which assists chemisorption process wherein the co-ordination bond has been created via inhibitor participation and/or electrons transition to MS surface atoms involving vacant-d-orbital, so the anodic reaction of the corrosion process take place [46]. 
On the other hand, a low $\mathrm{E}_{\mathrm{a}}$ value in the existence of inhibitor molecules matches up to free solution has been recommended chemisorption process of inhibitor molecules. The $\mathrm{E}_{\mathrm{a}}{ }^{*}$ values listed in Table 9 have been comparatively close and follow the same pattern, which agree with the transition-state theory model. Enthalpy of activation $\Delta H^{*}$ has a positive value, which has been signified that the metal dissolution process has been endothermic [47]. This also has been achieved to be investigated of delayed metal corrosion in inhibitor containing solution.

The Chicoriumintybus extract Entropy values $\left(\Delta \mathrm{S}^{*}\right)$ have been negative, referring that the rate determining step has been included association further than the dissociating phenomenon of activated complex creation [48]. From which, transition process from reactants to activated complex has been followed by lowering in a mess. In the inhibitors existence, the hydrogen ion discharge to create adsorbed hydrogen atoms at the metal surface can be blocked via the inhibitor molecule adsorption. This reasons allows the system to exceed further orderly to a less orderly arrangement.

The apparent activation energy $\left(\mathrm{E}_{\mathrm{a}}^{*}\right)$, the activation enthalpy $\left(\Delta \mathrm{H}^{*}\right)$ and the activation entropy $\left(\Delta \mathrm{S}^{*}\right)$ for the dissolution of MS samples in $1.0 \mathrm{M} \mathrm{HCl}$ solution in the existence and nonexistence of different Chicoriumintybus extract doses have been computed via Arrhenius and transition-state eqns. (10 \&11):

$$
\text { Rate }\left(\mathrm{k}_{\mathrm{corr}}\right)=\mathrm{A} \exp \left(-\mathrm{E}_{\mathrm{a}}^{*} / \mathrm{RT}\right)
$$

Rate $\left(\mathrm{k}_{\text {corr }}\right)=\mathrm{RT} / \mathrm{Nh} \exp \left(\Delta \mathrm{S}^{*} / \mathrm{R}\right) \exp \left(-\Delta \mathrm{H}^{*} / \mathrm{RT}\right)$

Where, $\mathrm{A}$ is the Arrhenius pre-exponential factor, $\mathrm{h}$ is the Plank's constant and $\mathrm{N}$ is Avogadro's number. Figure 11 represents, plot of $\log \mathrm{k}_{\text {corr }} v s .1 / \mathrm{T}$ in $1.0 \mathrm{M}$ $\mathrm{HCl}$ of different extract doses, as of the slope in Figure 11, the $\mathrm{E}_{\mathrm{a}}{ }^{*}$ data have been computed. Figure 12 illustrates a plot of $\log \mathrm{k}_{\mathrm{corr}} / \mathrm{T} v s .1 / \mathrm{T}$ gives a straight line its slope of $\Delta \mathrm{H} / 2.303 \mathrm{R}$ and intercepts of $\log \mathrm{R} / \mathrm{Nh}+\Delta \mathrm{S}^{*} / 2.303 . \mathrm{E}_{\mathrm{a}}{ }^{*}$ data of the inhibited solutions have been lower than that of uninhibited ones referring that the MS corrosion has been reduced via the creation of the inhibitor adsorption protective film on the MS surface. The calculated data of $\left(\mathrm{E}_{\mathrm{a}}^{*}\right),\left(\Delta \mathrm{H}^{*}\right)$ and $\left(\Delta \mathrm{S}^{*}\right)$ have been recorded in Table 9, which inform that:

i. The existence of examining extract reducing the $\mathrm{E}_{\mathrm{a}}{ }^{*}$ and consequently reducing the $\mathrm{CR}\left(\mathrm{k}_{\text {corr }}\right)$ of MS via forming a barrier to mass and charge transfer and by their adsorption on the MS surface.

ii. $\Delta \mathrm{H}^{*}$ positive signs be a sign of the endothermic nature of the MS dissolution process [49].

iii. The values of $\Delta \mathrm{S}^{*}$ in existence and nonexistence of examining extract has been negative, which refers to the activated complex in the rate-determining step characterizes an association rather than dissociation [50,51], which refer to the activated molecules have been in a less-order state than that at the initial state.

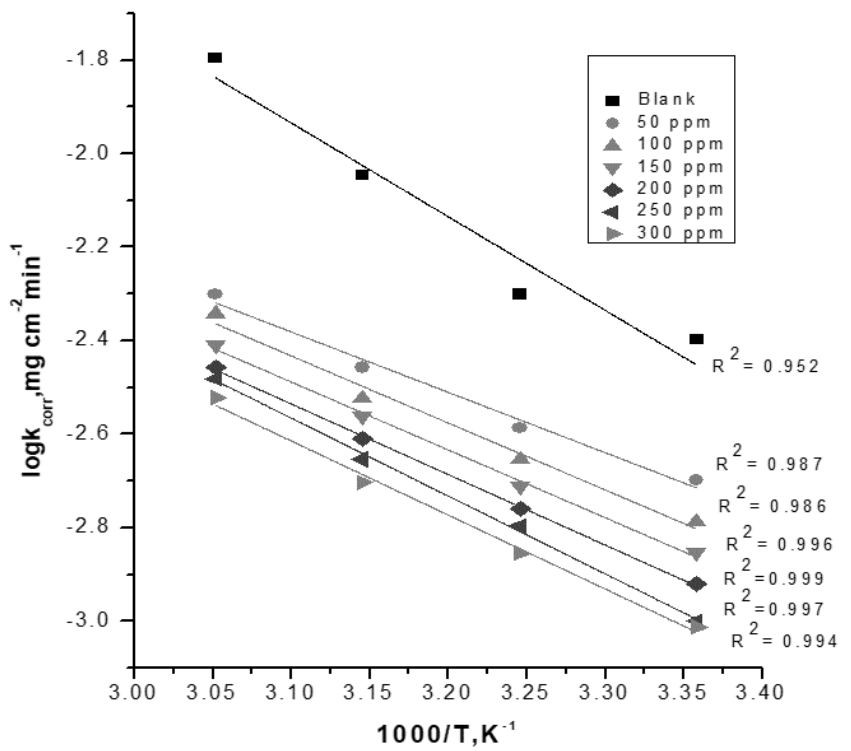

Figure 11. Arrhenius curves for $\mathrm{MS}$ corrosion in $1.0 \mathrm{M} \mathrm{HCl}$ in the existence and non existence of the different Chicoriumintybus extract doses.

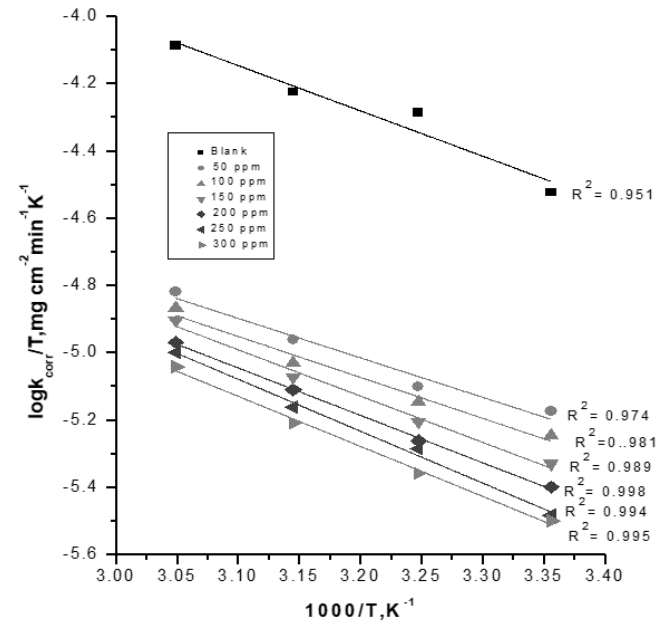

Figure 12. Transition-state for $\mathrm{MS}$ corrosion $\left(\log \mathrm{k}_{\text {corr }} / \mathrm{T}\right)$ in $1.0 \mathrm{M} \mathrm{HCl}$ in the existence and nonexistence of the different Chicoriumintybus extract doses.

Table 9. Activation parameters for MS in the existence and nonexistence of the different Chicoriumintybus extract doses in $1.0 \mathrm{M} \mathrm{HCl}$

\begin{tabular}{|c|c|c|c|}
\hline Conc., $\mathbf{p p m}$ & $\mathbf{E}_{\mathbf{a}}{ }^{*} \mathbf{~ k J ~} \mathbf{~ m o l}^{\mathbf{1}}$ & $\Delta \mathbf{H}^{*}, \mathbf{~ k J ~} \mathbf{~ m o l}^{\mathbf{1}}$ & $-\Delta \mathbf{S}^{*}, \mathbf{J} \mathbf{~ m o l}^{\mathbf{- 1}} \mathbf{K}^{-\mathbf{1}}$ \\
\hline Blank & 38.3 & 16.6 & -274.7 \\
\hline 50 & 30.6 & 15.8 & -289.5 \\
\hline 100 & 29.6 & 14.1 & -290.2 \\
\hline 150 & 26.8 & 13.3 & -291.1 \\
\hline 200 & 25.8 & 12.5 & -291.7 \\
\hline 250 & 24.8 & 11.6 & -292.9 \\
\hline 300 & 23.9 & 10.8 & -293.3 \\
\hline
\end{tabular}

\subsection{Surface analysis}

\subsubsection{Scanning electron microscopy (SEM)}

The MS surface examination via SEM instrument. Figures $13_{\text {[a-c] }}$ of the MS surface in $1.0 \mathrm{M} \mathrm{HCl}$ solution exhibits the transforms which happened through the corrosion process in the existence and nonexistence of the Chicoriumintybus extract. Figure $13_{\mathrm{a}}$ has been illustrated SEM image of polished MS with comparatively smooth surface, MS surface after inundation in $1.0 \mathrm{M} \mathrm{HCl}$ solution has been drastically damaged Figure $13_{\mathrm{b}}$, in the existence of $300 \mathrm{ppm}$ of the Chicoriumintybus extract, surface has been remarkably advanced Figure $13_{\text {c }}$. This advance in surface morphology is a sign of the protecting layer creation of the Chicoriumintybus extract on the MS surface that one is responsible for inhibition and reduction in the corrosion rate [52].

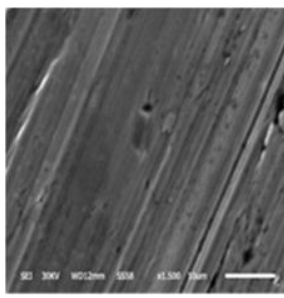

(a)

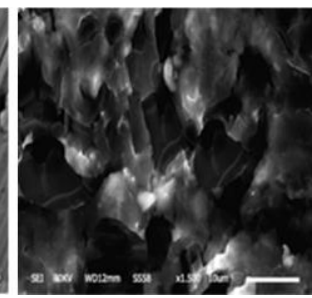

(b)

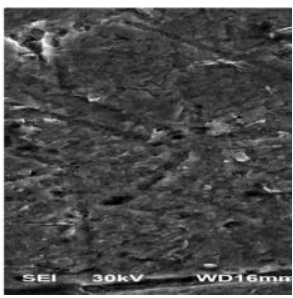

(c)
Figure 13. SEM images of MS surface (a) before of inundation in $1.0 \mathrm{M} \mathrm{HCl}$, (b) after $24 \mathrm{~h}$ of inundation in $1.0 \mathrm{M} \mathrm{HCl}$ and (c) after $24 \mathrm{~h}$ of inundation in 1.0 $\mathrm{M} \mathrm{HCl}+300 \mathrm{ppm}$ of the Chicoriumintybus extract at $25^{\circ} \mathrm{C}$.

\subsubsection{Atomic force microscopy (AFM)}

AFM has been a significant tool in order to estimate the surface morphology investigation that one have been helpful to discuss the inhibitor effect on the metal/solution interface [53]. Figures $14_{[a-c]}$, illustrated the AFM graphs of polished MS, MS in $1.0 \mathrm{M} \mathrm{HCl}$, which not including the Chicoriumintybus extract and $\mathrm{MS}$ in $1.0 \mathrm{M} \mathrm{HCl}$ containing $300 \mathrm{ppm}$ of the Chicoriumintybus extract, respectively. From AFM micrographs, the surface is very obvious for 
polished MS samples with average roughness $33.4 \mathrm{~nm}$ as shown in Figure 14a. Whereas in the nonexistence of the Chicoriumintybus extract, the MS surface has been more corroded, with average roughness $667.5 \mathrm{~nm}$ as shown in Figure 14. By comparison, the average roughness have been reduced to $147 \mathrm{~nm}$ in the existence of the Chicoriumintybus extract at the optimum dose (300 ppm) as shown in Figure 14. From the results, we concluded that the lowering in the roughness can be very well understand to be via the adsorbed protecting layer creation of the Chicoriumintybus extract on the MS surface.

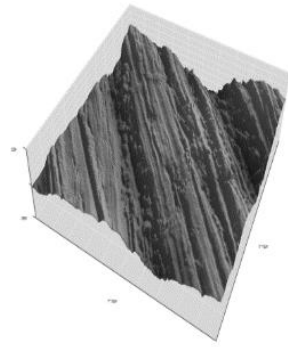

(a)

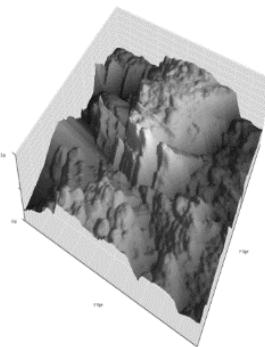

(b)

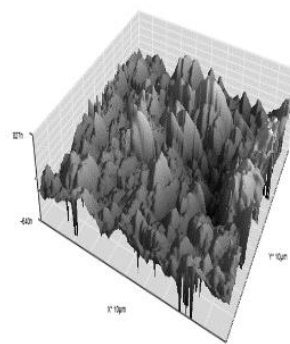

(c)
Figure 14. AEM images of MS surface (a) before of inundation in $1.0 \mathrm{M} \mathrm{HCl}$, (b) after $24 \mathrm{~h}$ of inundation in $1.0 \mathrm{M} \mathrm{HCl}$ and (c) after $24 \mathrm{~h}$ of inundation in 1.0 $\mathrm{M} \mathrm{HCl}+300 \mathrm{ppm}$ of Chicoriumintybus extract at $25^{\circ} \mathrm{C}$.

\subsubsection{Attenuated total reflection-infrared spectroscopy (ATR-IR)}

ATR-IR displays interesting features such as a high signal to noise ratio, high sensitivity and selectivity, accuracy, mechanical simplicity, short analysis time and small amount of sample required for the analysis. Figure 15 shows the ATRIR spectra of the Chicoriumintybus extract. The broad band obtained at $3335 \mathrm{~cm}$ ${ }^{1}$ can be assigned to $(\mathrm{O}-\mathrm{H})$, the one at $1643 \mathrm{~cm}^{-1}$ corresponds to $(\mathrm{C}=\mathrm{C})$, the $-\mathrm{C}=\mathrm{C}$ stretching frequency appears at $1455 \mathrm{~cm}^{-1}$, the band at $1378 \mathrm{~cm}^{-1}$ can be assigned to aromatic nitro compound stretching ,the sharp one at band at $1085 \mathrm{~cm}^{-1}$ corresponds to $(\mathrm{C}-\mathrm{O})$ stretch, the frequency at $1046 \mathrm{~cm}^{-1}$ is due to $\left(=\mathrm{CH}_{2},=\mathrm{C}-\mathrm{H}\right)$, the Nitrate $\mathrm{NO}_{2}$ bending frequency at $721 \mathrm{~cm}^{-1}$.

By comparing the spectra of the extract with that of the solid corrosion product shown in Figure 15, it is observed that there are shifts in the frequencies. It was found that $(\mathrm{O}-\mathrm{H})$ stretch at $3335 \mathrm{~cm}-1$ was shifted to $3332 \mathrm{~cm}^{-1}$, the $-\mathrm{C}=\mathrm{C}$ stretch at $1455 \mathrm{~cm}^{-1}$ was shifted to $1472 \mathrm{~cm}^{-1}$, the aromatic nitro compound at $1378 \mathrm{~cm}^{-1}$ has disappeared ,the (C-O) stretch at $1085 \mathrm{~cm}^{-1}$ was shifted to $1010 \mathrm{~cm}^{-1}$, the $\left(=\mathrm{CH}_{2},=\mathrm{C}-\mathrm{H}\right)$ stretch at $1046 \mathrm{~cm}-1$ was shifted to $950 \mathrm{~cm}^{-1}$, the Nitrate $\mathrm{No}_{2}$ bending frequency at $721 \mathrm{~cm}^{-1}$ has disappeared. The shifts in the spectra indicate that the interaction between the extract and mild steel that occurred through the functional groups found in it [54].

This study has been recommended that the Chicoriumintybus extract has been coordinated with $\mathrm{Fe}^{2+}$, through the oxygen atom of the hydroxyl groups, resulting in the $\mathrm{Fe}^{2+}$ - inhibitor complex creation on the metal surface anodic sites [55]. Thus, the ATR-IR spectral study shows the creation of the adsorbed layer consists of $\mathrm{Fe}^{2+}$ - inhibitor complex via chemisorptions process.

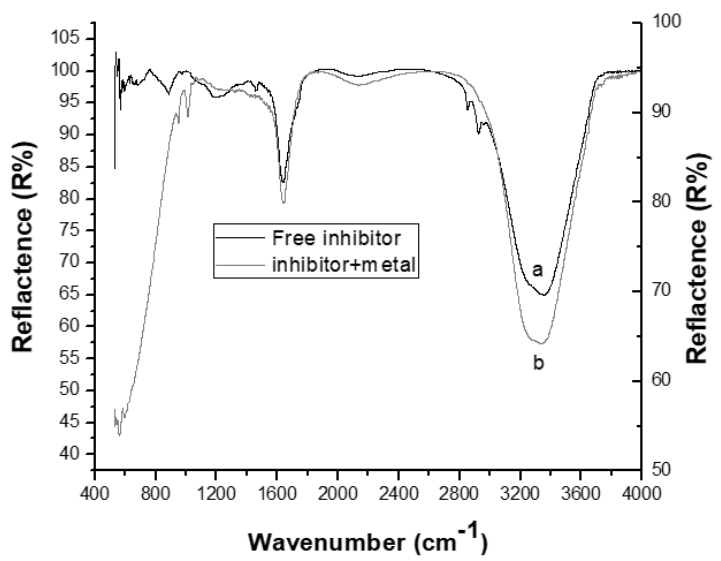

Figure 15. ATR-IR spectroscopy of (a) Chicoriumintybus extract and (b) the film formed on the MS surface after inundation in $1.0 \mathrm{M} \mathrm{HCl}+300 \mathrm{ppm}$ of Chicoriumintybus extract for $24 \mathrm{~h}$ at $25^{\circ} \mathrm{C}$.

\subsection{Mechanism of corrosion inhibition}

The extract adsorption may be explained via two main processes of interactions: physisorption and chemisorptions. Generally, physisorption needs the existence of both charged species in solution and metal surface which electrically charged. The metal surface charge of the electric field presented in the metal/solution interface. In contrast, a chemisorption process may include charge transfer or charge sharing from the inhibitor molecules to the metal surface to form a coordination bond. This has been achieved in the case of a positive as well as a negative charge on the metal surface. The transition metal existence in which involving vacant, low-energy electron orbital's $\left(\mathrm{Fe}^{2+}\right.$ and $\mathrm{Fe}^{3+}$ ) and the Chicoriumintybus extract molecules which having bound electrons or heteroatom's involving a lone pair of electrons have been essential for the large inhibiting action [56]. Commonly, there have been two kinds of inhibition mechanisms have been suggested. One has been the creation of polymeric complexes with iron ions $\left(\mathrm{Fe}^{3+)}\right.$ relying on the applied conditions [57], the other one has been the chemical adsorption of the Chicoriumintybus extract on the MS surface [58]. The inhibition achievement of the Chicoriumintybus extract doses hasn't been happened via the simple blocking at the MS surface, chiefly at high temperature. This could be referred to the dissimilar adsorption capacities of the Chicoriumintybus extract on the MS surface at different temperatures. We have been discussing that while rising temperature the Chicoriumintybus extract adsorption effect on MS surface raised. Most of the hydrophilic groups which have positively charged atoms $\left(\mathrm{O}^{+}\right)$adsorbed from the MS surface and influence to allow the $\mathrm{H}^{+}$became closer to the metal surface. As a result, the Chicoriumintybus extract has been preferred blocking both anodic and cathodic corrosion processes at higher temperatures as shown in Figure 16.

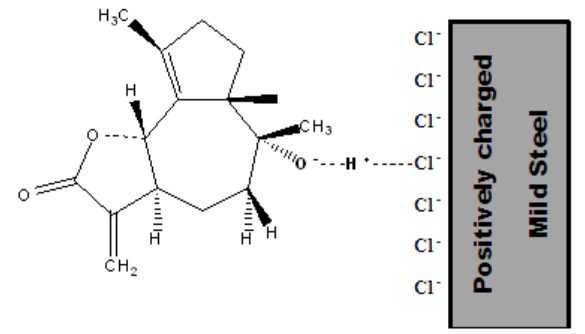

Figure 16. Possible adsorption process of protonated compound from Chicoriumintybus extract on mild steel surface in $1.0 \mathrm{M} \mathrm{HCl}$.

\section{CONCLUSION}

The inhibition efficiency IE\% raises by rising the Chicoriumintybus extract doses and increases as the temperature rising as illustrated in Figure 17. Adsorption of the Chicoriumintybus extract molecules on the MS surface is found to obey Temkin adsorption isotherm model. Polarization curves referred that the Chicoriumintybus extract acted as a mixed type inhibitor. ATR-IR spectrum approved that the extract adsorbed on the metal surface. ATR-IR, SEM and AFM images indicated the possibility of creation of the protecting layer on the MS surface. Derived from all results of ML, PP, EIS and EFM, the Chicoriumintybus extract had been shown as an effective inhibitor for MS in 1.0 $\mathrm{M} \mathrm{HCl}$.

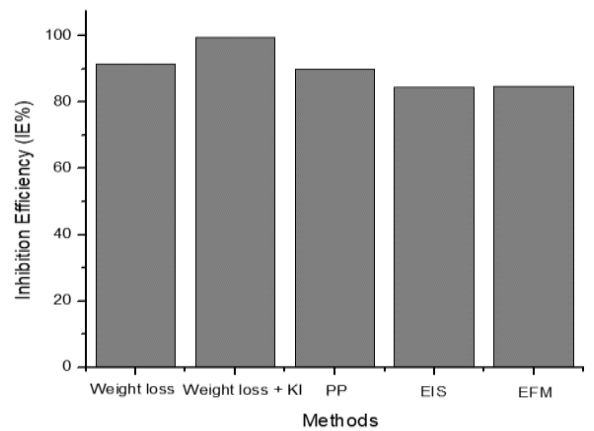

Figure 17. Comparison of inhibition efficiency (IE\%) resulted from experimental methods for corrosion of MS in $1.0 \mathrm{M} \mathrm{HCl}$ containing $300 \mathrm{ppm}$ of Chicoriumintybus in addition to (IE\%) resulted from (300 ppm of Chicoriumintybus $+1 \mathrm{ml} \mathrm{KI}$ ) at $25^{\circ} \mathrm{C}$. 


\section{REFERENCES}

1. N. K. Bakirhan, A. Asan, N. Colak, S. Sanli, J Chil Chem Soc 61, 3066, (2016).

2. Evrim Baran, Ahmet Cakir, BirgülYazici Arab. J. Chem 3, 1, (2016).

3. Noha Fathalla, Mokhtar Bishr, Abdel-Nasser Singab, and Osama Salama, IOSR-JPBS 10, 70, (2015).

4. N. Lebe, N. Geoerge, N. Justus, E. Nneka, and E. peter, Int J Mat Chem 6, 2, (2016).

5. A. Yildirim and M. Cetin, Corros Sci 5, 155, (2008).

6. Abd El-Aziz S. Fouda, Ayman Y. El-Khateeb, Nabila M. Elbahrawi, Zastita Materijala 58, 131, (2017).

7. H. H. Karim, A. K. Anees and H. K. Noor, SAJCE 22, 1, (2016).

8. L. G. Da Trindade and R. S. Goncalves, Corros Sci 51, 1578, (2009).

9. Marko Chigondo and Fidelis chigondo, J Chem 2016, 7 pages, (2016).

10. Saviour A. Umoren, Moses M. Solomon, Ime B. Obot, \& Rami K Suleiman, J Adhes Sci Technol 17, 1934, (2018).

11. S. A. Umoren, I. B. Obot, Z. M. Gasem, Ionics 21, 1171, (2015).

12. N. Soltani and M. Khayatkashani, Int J Electrochem Sci 10, 46, (2015).

13. K. K. Anupama, K. Ramya, and A. Joseph, Measurement 95, 297, (2017).

14. M. H. Hazwan, M. J. Kassim, N. N. Razali, N. H. Dahon and D. Nasshorudin, Arab J Chem 9, S616, (2016).

15. T. H. Ibrahim, E. E. Gomes, I. B. Obot, M. Khamis, and M. A. Sabri, J Adhes Sci Technol 31, 2697, (2017).

16. S. Perumal, S. Muthumanickam, A. Elangovan, R. Karthik, and K. K. Mothilal, J Bio Tribo-Corr 3, 1, (2017).

17. E. B. Ituen, A. O. James and O. Akaranta, JMES 8, 1498, (2017).

18. L. L. Liao, S. Mo, H. Q. Luo, and N. B. Li, J Colloid Interf Sci 499, 110, (2017).

19. E. Ituen, O. Akaranta, A. James and S. Sun, J SM\&T 11, 12, (2017).

20. H. L. Y. Sin, A. A. Rahim, C. Y. Gan, B. Saad, M. I. Salleh and M. Umeda, Measurement 109, 334, (2017)

21. S. Nandagopal and B. D. Ranjitha Kumari, Adv Biol Res 1, 17, (2007).

22. R. Kumari, M. Ali, and V. Aeri, J Asian Nat Prod Res 14, 7, (2012).

23. Heibatollah, S. Reza, Nikbakht Mohammad; Izadpanah Ghaitasi, Sohailla Sabzali, Afr J Biochem Res 2, 141, (2008).

24. R. Baskar, D. Kesavan, M. Gopiraman, Prog Org Coat 77, 836, (2014).

25. M. A. Migahed, E. G. Zaki, M. M. Shaban, RSC Adv 6, 71384, (2016).

26. K. K. Anupama, K. Ramya and A. Joseph, Measurement 95, 297, (2017).

27. Abd El-Aziz Fouda, Ahmed Al-Sarawy and Emad El-Katori, Europ J Chem 1, 312, (2010).

28. Dr. Rathika. Govindasamy, Swetha Ayappan, J Chil Chem Soc 60, 2786, (2015).

29. Abd El-Aziz S. Fouda, Safaa El-din H. Etaiw, Dina M. Abd El-Aziz and Osama A. Elbaz, Int J Electrochem Sci 12, 5934, (2017).

30. Husnu Gerengia, H. Ibrahim Ugrasb, Moses M. Solomonc, Saviour A. Umorend, Mine Kurtaya and Necip Atare, J Adhes Sci Technol 30, 2383, (2016).

31. Abd El-Aziz S. Fouda, Ali M. El-Azaly, J Bio Tribo Corros 3, 49, (2017).

32. M. Bouanis, M. Tourabi, A. Nyassi, A. Zarrouk, C. Jama, F. Bentiss, Appl Surf Sci 389, 952, (2016).
33. A. S. Fouda, T. Fayed, M. A. Elmorsi, M. Elsayed, J Bio Tribo Corros 3, 1 (2017).

34. J. DAHDELE, I. DANAEE, G.R. RASHED, J Chil Chem Soc 61, 3025, (2016).

35. Y. Zhou, S. Zhang, L. Guo, S. Xu, H. Lu and F. Gao, Studies Int J Electrochem Sci 10, 2072, (2015).

36. Ashish Kumar Singh, Sanjeeve Thakur, Balaram Pani, Eno E. Ebenso, Mumtaz Ahmad Quraishi, and Ajit Kumar Pandey, ACS Omega 3, 4695, (2018).

37. K. R. Ansari, M. A. Quraishi, A. S. Ramkumar and I. B. Obot, RSC Adv 6, 24130, (2016).

38. A. Biswas, S. Pal and G. Udayabhanu, Appl Surf Sci 353, 173, (2015).

39. El Bribri, M. Tabyaoui, B. Tabyaoui, H. El Attari, F. Bentiss, Mat Chem Phys 141, 240, (2013).

40. Abd El-Aziz S. Fouda, Emad E. El-Katori and Saedah Al-Mhyawi, Int J Electrochem Sci 12, 9104, (2017).

41. L. O. Olasunkanmi, I. B. Obot and E. E. Ebenso, RSC Adv 6, 86782, (2016).

42. K. K. Alaneme, Y. S. Daramola, S. J. Olusegun and A. S. Afolabi, Int J Electrochem Sci 10, 3553, (2015).

43. A. S. Fouda, S. A. Abd El-Maksoud and H. M. Mostafa, J Appl Chem 6, 190, (2017).

44. Fouda, M. Ismail, G. EL-ewady and A. Abousalem, J Mol Liq 240, 372, (2017).

45. S. Fouda, A. M. Attiab and A. M. Rashed, Prot Met Phys Chem 53, 743, (2017).

46. Abd El-Aziz S. Fouda, Ahmed A. El-Hossiany, Heba M. Ramadan, Zastita Materijala, 58, 541, (2017).

47. N. Soltani, N. Tavakkoli and M. Ghasemi, Int J Electrochem Sci 11, 8827, (2016).

48. Verma, P. Singh, I. Bahadur, E. E. Eenso, and M. A. Quraishi, J Mol Liq 209, 767, (2015)

49. R. Karthik, P. Muthukrishnan, A. Elangovan, B. Jeyaprabha, and P. Prakash, Adv Civil Eng Mat 3, 413, (2014).

50. M. Pitchaipillai, K. Raj, J. Balasubramanian, and P. Periakaruppan, Inter J Min Metall Mat 21, 1083, (2014).

51. Anees A. Khadom, J Chil Chem Soc 59, 2545, (2014).

52. Ambrish Singh, Mohd Talha, Xihua Xu, Zhipeng Sun, and Yuanhua Lin; ACS Omega 2, 8177, (2017).

53. Wang, M. Du Zhang and J. Gao, Corros Sci 53, 354, (2011).

54. R. Vera, R. Schrebler, P. Cury, R. Del Rio, and H. Romero, J Appl Electrochem 37, 519, (2007).

55. A. Ehsani, M. G. Mahjani, M. Hosseini, R. Safari, R. Moshrefi and H. M. Shiri, J Colloid Interf Sci 490, 444, (2017).

56. A. S. Fouda, A. Emam, R. Refat, M. Nageeb, J Anal Pharm Res 6, 00168, (2017).

57. A. S. Fouda, S. A. Abd El-Maksoud, M. Sh. Zoromba, and A. R. Ibrahim, Int J Corros Scale Inhib 6, 372, (2017). D. Mares, Carlo Romagnoli B. Tosi, Elisa Andreotti, G. Chillemi and F. Poli, 160, 85, (2005).

58. D. Mares, Carlo Romagnoli B. Tosi, Elisa Andreotti, G. Chillemi and F. Poli, $160,85,(2005)$. 